\title{
Desain Interior Pelayanan Maternal-Neonatal RSI Jemursari berkonsep Natural Modern untuk Menunjang Efektivitas Kerja
}

\author{
Yasmine Mawaddah Ghufrona dan Budiono \\ Departemen Desain Interior, Fakultas Teknik Sipil dan Perencanaan, Institut Teknologi Sepuluh Nopember (ITS) \\ e-mail: yasmineghufrona@gmail.com
}

\begin{abstract}
Abstrak-Peran rumah sakit sebagai fasilitas dalam meningkatkan derajat kesehatan masyarakat semakin dituntut untuk dapat memberikan pelayanan yang bermutu. RSI Jemursari adalah rumah sakit swasta tipe $B$ yang terdiri dari berbagai unit kesehatan, diantaranya adalah Unit Mawar untuk Pelayanan kesehatan Maternal dan Neonatal. RSI Jemursari menerapkan program kesehatan PONEK yang berfokus pada pelayanan kesehatan emergensi dan komprehensif. Dalam mewujudkan misi dan visi RSI Jemursari untuk menjadi rumah sakit islam berstandar internasional, diperlukan konsep desain yang dapat menunjang efektivitas kerja pelayanan dan juga kenyamanan pasien. Langgam Natural Modern yang mengunggulkan efisiensi ruang dengan pendekatan terapi taman diterapkan pada elemen-elemen desain interior. Proses tahapan desain menggunakan metode desain melalui pengumpulan data, studi literatur, analisa data untuk mengidentifikasi masalah dan pembentukan konsep desain. Hasil desain adalah konsep desain interior yang dapat menunjang efektivitas kerja pelayanan kesehatan di RSI Jemursari. Perancangan desain interior ini diharapkan dapat memfasilitasi Unit Mawar RSI Jemursari untuk dapat menjalankan tugasnya dalam meningkatkan derajat kesehatan ibu dan bayi.
\end{abstract}

Kata Kunci-Efektivitas Kerja, Natural Modern, Pelayanan Maternal-Neonatal RSI Jemursari.

\section{PENDAHULUAN}

$\mathrm{P}$ ENYELENGGARAAN pelayanan kesehatan merupakan salah satu upaya dalam meningkatkan derajat kesehatan masyarakat. Peran rumah sakit sebagai fasilitas pelayanan kesehatan semakin dituntut untuk dapat meningkatkan pelayanan yang bermutu. Pelayanan yang bermutu dapat ditinjau dari kompetensi teknis sang pelaksana medis, akses pelayanan, keamanan dan kenyamanan bangunan rumah sakit. Sehingga, dalam mewujudkan pelayanan kesehatan yang bermutu dibutuhkan tercapainya efektivitas kerja dari berbagai sarana dan prasarana dari rumah sakit.

Rumah sakit adalah suatu organisasi yang melalui tenaga medis profesional yang terorganisir serta sarana kedokteran yang permanen menyelenggarakan pelayanan kesehatan, asuhan keperawatan yang berkesinambungan, diagnosis serta pengobatan penyakit yang diderita oleh pasien. Salah satu fasilitas kesehatan rumah sakit yang dikhususkan untuk kesehatan maternal (kandungan) dan neonatal (bayi) disusun dalam program kesehatan PONEK (Pelayanan Obstetri Neonatal Emergensi Komprehensif). PONEK merupakan program pelayanan kedaruratan maternal dan neonatal secara komprehensif dan terintegrasi 24 jam dalam sehari.

Rumah Sakit Islam (RSI) Jemursari adalah rumah sakit swasta tipe B yang telah beroperasi sejak tanggal 25 Mei 2002. RSI Jemursari menyediakan unit Mawar yang dikhususkan untuk pelayanan kesehatan maternal dan neonatal. RSI Jemursari menerapkan program PONEK sejak tahun 2015 dan telah diakui sebagai rumah sakit MAMPU PONEK. Fasilitas pelayanan maternal dan neonatal di RSI Jemursari terdiri dari ruang bersalin, ruang rawat inap, NICU bayi, ruang laktasi dan sebagainya.

Pada desain interior di pelayanan maternal dan neonatal RSI Jemursari ditemukan beberapa permasalahan desain yang dapat menghambat proses pelayanan, diantaranya adalah kurang optimalnya efisiensi ruang dan privasi pasien. Mengetahui pertolongan untuk kesehatan maternal dan neonatal membutuhkan tindakan yang cepat, maka dibutuhkan konsep desain interior yang dapat menunjang efektivitas pelayanan. Fungsionalitas ruang dan penegasan pada area privat diperlukan agar proses pelayanan terhindar dari gangguan dan dapat terlaksana dengan baik.

Kepuasan pasien adalah kunci dalam menilai mutu pelayanan. Dalam hal ini, pasien maternal dan neonatal membutuhkan lingkungan rumah sakit yang dapat menghadirkan kenyamanan secara fisik dan emosional. Terapi taman dapat membantu dalam kecepatan penyembuhan pasien. Pendekatan dengan unsur alam seperti tumbuhtumbuhan dapat memberikan ketenangan pada pikiran. Sehingga, desain interior bernuansa natural perlu diterapkan pada rumah sakit untuk mengurangi tingkat kecemasan dan mempercepat penyembuhan pasien.

Berdasarkan latar belakang diatas, maka dibutuhkan redesain interior pada Pelayanan Maternal dan Neonatal RSI Jemursari dengan konsep efektivitas ruang guna mencapai pelayanan yang bermutu. Untuk menunjang kebutuhan tersebut maka digunakan langgam Natural Modern yang menonjolkan efisiensi dan optimalis ruang dengan unsur alam. Perancangan desain interior ini diharapkan dapat memfasilitasi pelayanan maternal dan neonatal di RSI Jemursari untuk dapat menjalankan tugasnya sebagai pelayanan kesehatan dan meningkatkan derajat kesehatan masyarakat.

\section{STUDI PUSTAKA}

\section{A. Efektivitas Pelayanan Kesehatan}

Menurut Wijono (1995) ada 8 dimensi mutu pelayanan 
kesehatan yang dapat membantu pola pikir dalam menetapkan masalah yang ada untuk mengukur sampai sejauh mana telah dicapai standar dan efektivitas pelayanan kesehatan. Kedelapan dimensi mutu tersebut adalah: a) Kompetensi teknis, b) Akses terhadap pelayanan kesehatan, c) Efektivitas mutu pelayanan, d) Hubungan antar manusia, d) Efisiensi pelayanan, e) Keberlangsungan pelayanan, f) Keamanan dan g) Kenyamanan.

\section{B. Konsep Natural Modern}

Natural (alam) berasal dari kata latin natura yang secara harfiah berarti kelahiran, yang terkait dengan karakteristik bawaan yang dimiliki tanaman, hewan dan berbagai fitur lain di dunia (Wikipedia). Menurut Sheila Semrou (2015), elemenelemen natural memiliki efek yang baik dalam hal medis jika diaplikasikan dalam fasilitas kesehatan. Elemen-elemen natural tersebut diantaranya adalah pencahayaan alami, pemandangan alam, penggunaan aspek alam melalui warna, suara, tekstur, material dan bentuk.

Konsep Modern berawal dari semangat minimalisme, yang mengarah pada fungsionalitas sebuah ruangan. Gerakan spirit minimalisme-fungsional merupakan gerakan baru yang mengarah pada efisiensi dan efektivitas penggunaan ruang dan perabotnya (Wicaksono dan Tisnawati, 2014). Karakteristik dari konsep Modern adalah pengutamaan fungsi terhadap bentuk, penggunaan warna-warna minimal dan bentuk geometris.

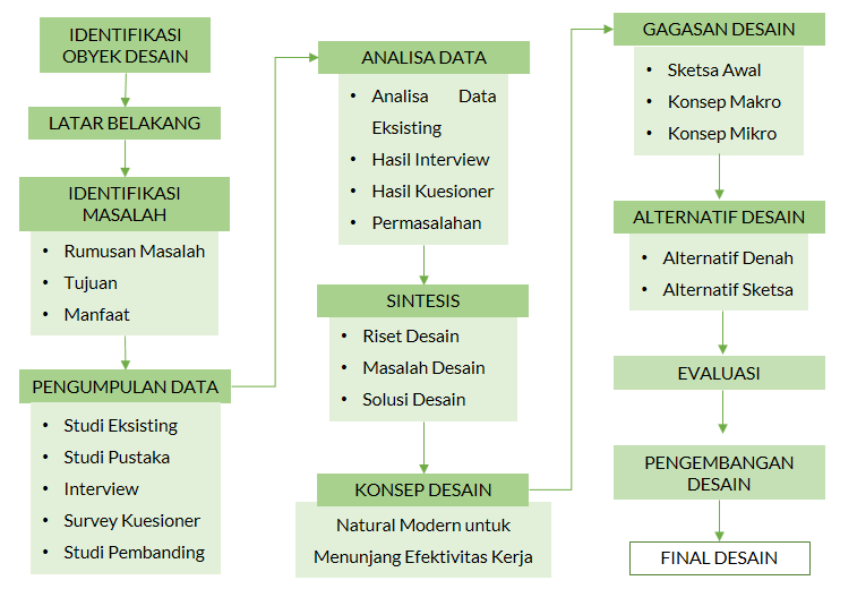

Gambar 1. Diagram Proses Desain

Sumber: Dokumentasi Penulis (2017)

\section{URAIAN PENELITIAN}

Metode desain dalam menuju desain akhir memiliki urutan proses sebagai berikut:

1. Pengumpulan Data, jenis-jenis data yang digunakan dalam metode penelitian adalah: a) data primer: data internal dari pihak rumah sakit, b) data observasi: data yang didapat penulis dari observasi langsung, dan c) data kuesioner: data analisa hasil riset.

2. Analisa Data, metode analisa yang digunakan adalah analisa induktif, deskriptif dan komparatif dengan mengolah data yang telah didapat.
3. Kesimpulan, proses pembentukan hasil analisa data dengan menyesuaikan studi literature menjadi konsep desain. Proses desain dilakukan dengan membentuk gagasan desain berupa konsep makro dan mikro

4. Proses Desain, proses pembentukan konsep desain menjadi desain nyata. Proses desain kemudian dilanjutkan dengan pembuatan alternatif desain, sketsa dan gambar kerja.

5. Desain Akhir, perwujudan dari konsep desain menjadi presentasi desain.

\section{KONSEP DESAIN}

\section{A. Konsep Makro}

1) Modern
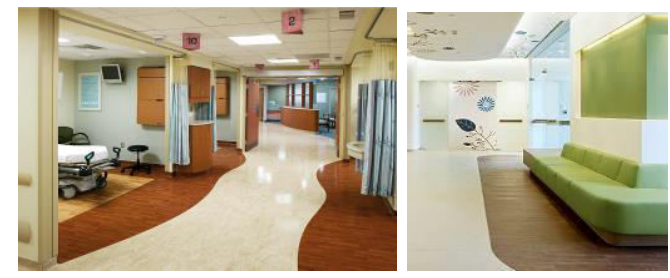

Gambar 2. Ilustrasi Konsep Modern

Sumber: Dokumentasi Penulis (2017)

a) Mementingkan unsur keterbukaan, kelapangan dan meminimalisir penyekatan dinding untuk mempermudah sirkulasi pelayanan.

b) Mengutamakan pada fungsi dari ruang dan efisiensi ruang dengan lebih maksimal dengan penggunaan furnitur yang praktis dan multifungsi.

c) Penggunaan warna-warna minimal dan bentuk geometris sederhana.

2) Natural
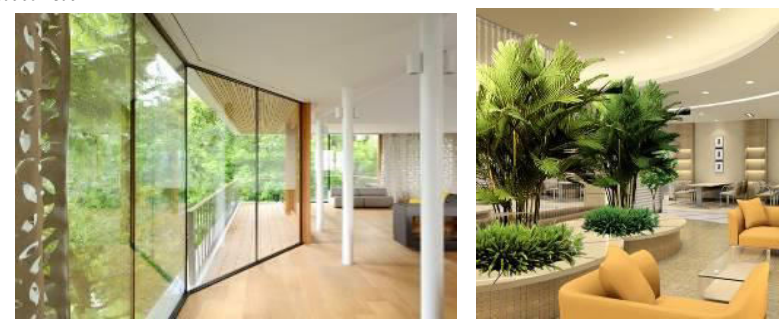

Gambar 3. Ilustrasi Konsep Natural

Sumber: Dokumentasi Penulis (2017)

a) Mengoptimalkan sirkulasi udara segar yang sehat dan pencahayaan sinar matahari yang berlimpah dengan penggunaan bukaan yang lebar.

b) Menghadirkan material tumbuhan dan bunga ke dalam ruang secara artificial dan visualisasi grafis.

c) Mengaplikasikan bunga dan tanaman sebagai elemen estetis.

d) Penggunaan material alami seperti kayu, batu, rotan, katun untuk membangkitkan unsur keselarasan dengan alam.

\section{B. Konsep Mikro}

1) Konsep Dinding 

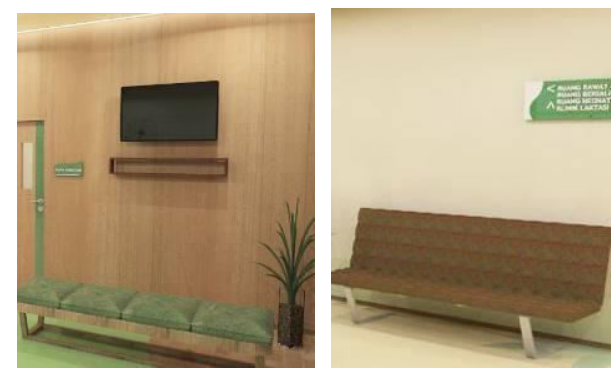

Gambar 4. Konsep Dinding

Sumber: Dokumentasi Penulis (2017)

Finishing dinding dibuat bervariasi dalam tiap ruang untuk membangkitkan keceriaan dalam ruang. Beberapa bagian dinding menggunakan finishing wallpaper bercorak kayu. Wallpaper bercorak kayu digunakan karena elemen bertekstur alam dapat membantu meringankan pikiran pada pasien.

\section{2) Konsep Lantai}

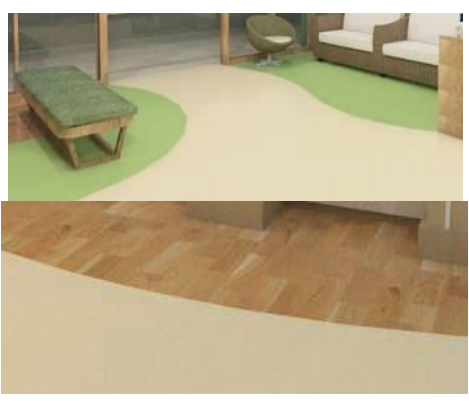

Gambar 5. Konsep Lantai

Sumber: Dokumentasi Penulis (2017)

Lantai vinyl digunakan karena sesuai dengan standar rumah sakit yang memiliki persyaratan lantai yang hygienis, mudah dibersihkan dan tidak mudah menyerap debu.

Corak tekstur lantai vinyl yang digunakan adalah corak polos (solid) berwarna krem muda, hijau muda dan corak kayu. Vinyl warna krem digunakan sebagai basis utama, sedangkan vinyl warna hijau dan corak kayu digunakan sebagai aksentuasi

\section{3) Konsep Plafon}

Gambar 6. Konsep Plafon

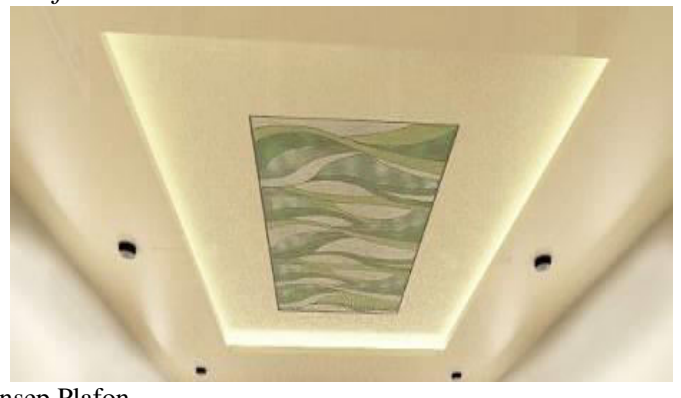

Sumber: Dokumentasi Penulis (2017)

Stained glass ceiling adalah kaca warna bercorak dengan lampu LED dibaliknya yang diterapkan pada plafon. Corak floral digunakan pada stained glass sebagai pencahayaan aksentuasi.
Stained glass ceiling diaplikasikan pada ruang-ruang yang digunakan oleh pasien dan pengunjung seperti lobby, kamar rawat inap dan ruang laktasi sebagai elemen estetis yang bertujuan untuk menyenangkan suasana hati pengguna.

\section{4) Pencahayaan}
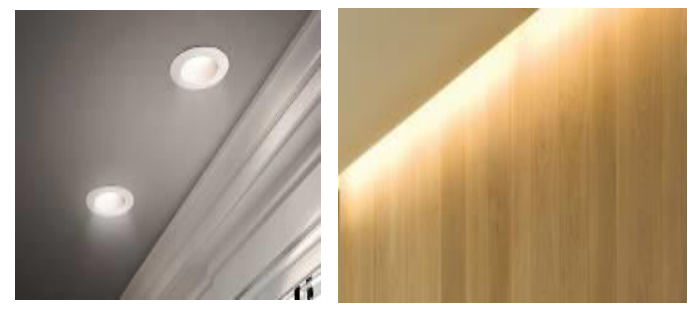

Gambar 7. Konsep Desain Pencahayaan Buatan Sumber: Dokumentasi Penulis (2017)

Pencahayan buatan yang digunakan adalah lampu TL, downlight, cove lighting dan LED. Untuk memenuhi persyaratan pencahayaan rumah sakit yang harus merata dan jelas, digunakan lampu downlight berwarna putih (2500-5300 $\mathrm{K})$.

Gambar 8. Konsep Desain Pencahayaan Alami

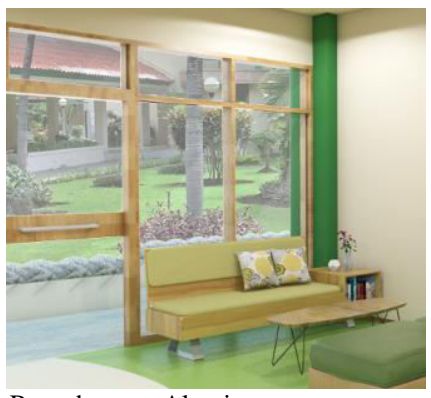

Sumber: Dokumentasi Penulis (2017)

Pencahayaan alami juga dimanfaatkan sebagai pencahayaan pada siang hari. Setiap ruang memiliki bukaan jendela yang lebar sehingga pemandangan eksterior dan cahaya matahari dapat dirasakan dari dalam ruang

\section{5) Furnitur}

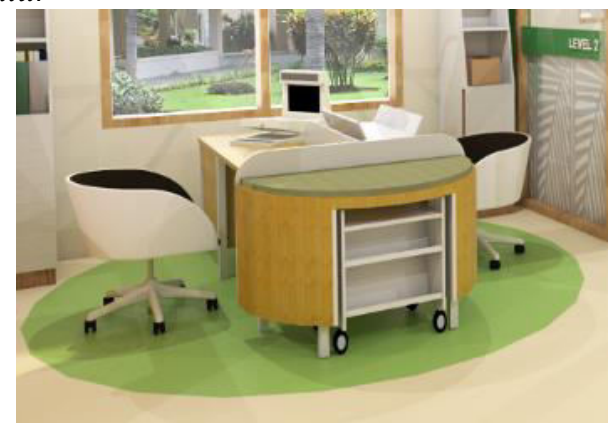

Gambar 9. Konsep Desain Furnitur

Sumber: Dokumentasi Penulis (2017)

Furnitur yang digunakan adalah furnitur modern yang memiliki bentuk geometris sederhana dan fungsional. Furnitur yang fungsional digunakan untuk memudahkan efisiensi kerja pelayanan, terutama pada kasus emergensi yang membutuhkan tindakan yang tepat dan cepat. 


\section{6) Elemen Estetis}

Gambar 10. Wallpaper Floral

Sumber: Dokumentasi Penulis (2017)

Elemen estetis yang digunakan merupakan bentuk pengaplikasian tanaman dan bunga ke dalam ruang. Motif floral berupa grafis dan handcraft diterapkan pada sarung bantal dan curtain. Bentukan bunga digunakan untuk memberikan nuansa ceria pada ruang.

Gambar 11. Kaligrafi artwork

Sumber: Dokumentasi Penulis (2017)

Kaligrafi artwork berupa tipografi timbul dipajang pada beberapa dinding sebagai simbolisasi Rumah Sakit Islam Jemursari. Kaligrafi yang digunakan berasal dari kalimat Do'a sebagai bentuk rasa sayang pada pasien dan penanaman nilai islam.

\section{HASIL DESAIN}

Langgam Natural Modern diterapkan pada desain interior pelayanan maternal-neonatal RSI Jemursari untuk menunjang efektivitas kerja para pengguna utama rumah sakit, yaitu pelaksana medis dan pasien.

\section{A. Area Pelayanan Neonatal (NICU)}

Area Pelayanan Neonatal terdiri dari NICU dan ruang laktasi yang memberikan perawatan kesehatan bayi. Pada ruang NICU diterapkan konsep sirkulasi terbuka dengan penggunaan partisi kaca untuk memudahkan perawat mengawasi bayi. Desain meja kerja perawat berkonsep multifungsi dengan kombinasi antara meja periksa, meja tulis dan troli instrumen.
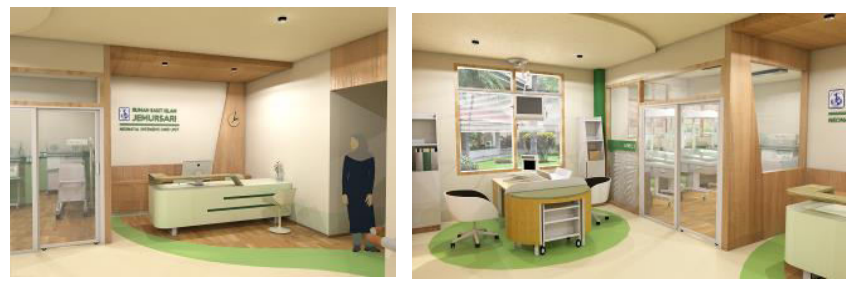

Gambar 12. Ruang NICU

Sumber: Dokumentasi Penulis (2017)

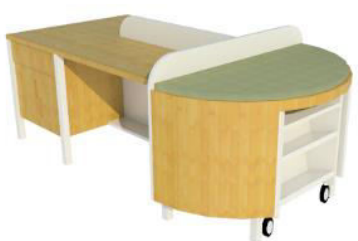

Gambar 13. Meja Kerja Perawat

Sumber: Dokumentasi Penulis (2017)

Ruang laktasi merupakan ruang khusus yang disediakan untuk ibu menyusui bayinya. Pada ruang laktasi tersedia sofa untuk para ibu yang ingin sharing mengenai laktasi. Selain itu juga disediakan ruang tertutup untuk menyusui privat. Nuansa natural diterapkan melalui penggunaan material kayu dan warna hijau yang dominan. Pada dinding terdapat kaligrafi artwork sebagai elemen estetis dengan kalimat Do'a untuk memberikan motivasi pada ibu untuk menyusui.

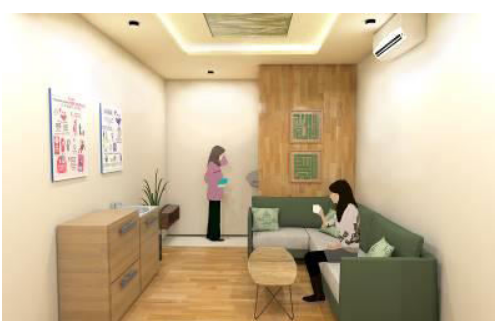

Gambar 14. Ruang Laktasi

Sumber: Dokumentasi Penulis (2017)
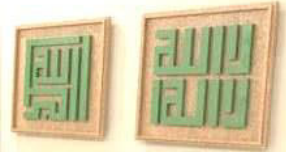

Gambar 15. Kaligrafi Do'a

Sumber: Dokumentasi Penulis (2017)

\section{B. Lobby}

Lobby berfungsi sebagai tempat keluarga pasien menunggu saat pasien menjalani proses perawatan. Lobby terbagi menjadi dua area yaitu area duduk dan informasi. Area duduk dilengkapi dengan fasilitas entertainment seperti rak buku dan televisi. Area duduk berhadapan dengan area informasi seperti pos perawat dan layanan mandiri untuk memudahkan pengguna mencari informasi.

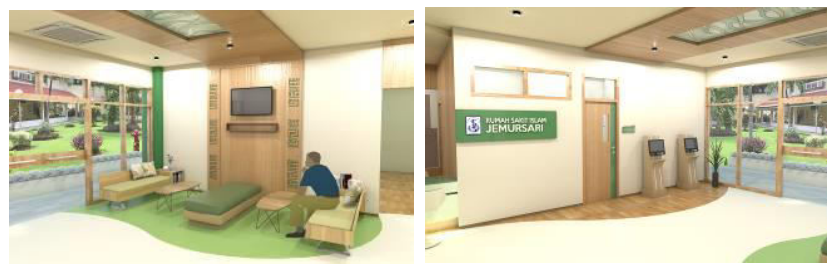

Gambar 16. Area Duduk dan Area Informasi Sumber: Dokumentasi Penulis (2017) 


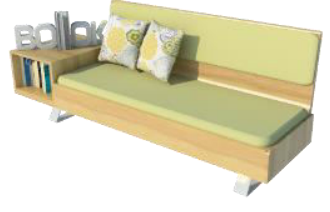

Gambar 17. Sofa Rak Buku

Sumber: Dokumentasi Penulis (2017)

\section{Ruang Rawat Inap VIP}

Ruang rawat inap merupakan ruang yang paling sering digunakan pasien selama berada di rumah sakit. Ruang rawat inap VIP A didesain dengan konsep natural modern agar dapat memberikan ketenangan pada pasien. Furnitur dalam ruang memiliki bentuk yang minimalis dan modern. Material pada ruang mayoritas menggunakan material dengan motif kayu dengan aksentuasi berwarna hijau. Warna hijau merupakan representasi dari RSI Jemursari dan sekaligus memberikan nuansa alam yang kuat.
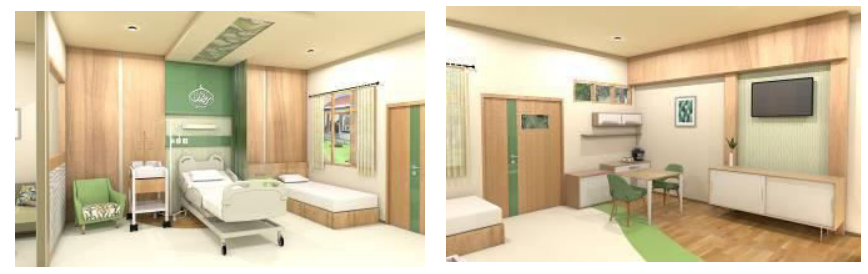

Gambar 18. Ruang rawat inap VIP A

Sumber: Dokumentasi Penulis (2017)

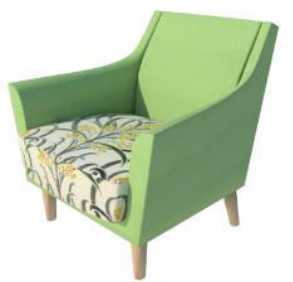

Gambar 19. Sofa Laktasi

Sumber: Dokumentasi Penulis (2017)

Sistem rawat inap gabung ibu dan bayi diterapkan di RSI Jemursari untuk mendukung program PRO-ASI. Pada samping bed pasien disediakan sofa laktasi untuk pasien ibu menyusui bayinya. Sofa laktasi ini memiliki konsep minimalis dan elegan yang dikhususkan untuk pengguna wanita, namun tetap menyesuaikan kenyamanan ergonomis pengguna.

\section{KESIMPULAN}

1. Desain interior untuk rumah sakit perlu mengikuti ketentuan bangunan rumah sakit yang telah ditentukan oleh Departemen Kesehatan RI.

2. Konsep desain interior Efektivitas Kerja berlanggam Natural Modern bertujuan untuk menunjang kinerja pelayanan kesehatan dan melalui terapi taman dapat memberikan suasana rumah sakit yang menyehatkan bagi pasien.

3. Perlu dilakukan studi teori rumah sakit dan kesehatan untuk menelaah lebih dalam mengenai kebutuhan psikologi pasien.

\section{DAFTAR PUSTAKA}

[1] Republik Indonesia (2009). Undang-Undang No. 36 Tahun 2009 tentang Kesehatan. Lembaran Negara RI Tahun 2009, No. 144. Jakarta: Sekretariat Negara.

[2] Wijono, D. (1999). Manajemen Mutu Pelayanan Kesehatan. Surabaya: Airlangga University Press.

[3] American Hospital Association (1974). Hospital Engineering Handbook. American Hospital Association.

[4] Menteri Kesehatan Republik Indonesia (2012). Pedoman Penyelenggaraan PONEK 24 Jam. Jakarta: Departemen Kesehatan.

[5] Rumah Sakit Islam Jemursari (2016). Tersedia: http://rsisjs.id/ [2 November 2016]

[6] Simkin, P. (1995). Reducing Pain and Enhancing Progress In Labour: A Guide Nonpharmacologic Methods for Maternity Caregivers. Birth 22:3, page 161-171.

[7] Semrou, Sheila (2015). Natural elements for health care interiors. Tersedia: http://www.hfmmagazine.com/articles/1665-natural-elementsfor-health-care-interiors [20 Oktober 2016]

[8] Haryanti (2000). Manajemen Mutu Pelayanan Kesehatan. Surabaya: Universitas Airlangga.

[9] Tietz, Jürgen (1999). The Story of Architecture in the 20th Century. Cologne: Konemann.

[10] Wicaksono dan Tisnawati (2014). Teori Interior. Jakarta: Griya Kreasi.

[11] Kristianto, Thomas A.(2016). Perancangan Interior Kantor Pusat PT Pelindo 3 (Persero) dengan Penerapan Konsep Seni Nusantara untuk Peningkatan Efisiensi dan Produktifitas Kerja. Jurnal Desain Interior. Vol. 1, 61-68.s

[12] Rachmaniyah, Nanik (2016). Studi Langgam Desain sebagai Dasar Mendesain Hotel. Jurnal Desain Interior. Vol. 1, 1-10.

[13] Lin, Lin, Li (2014). Planting Hope in Loss and Grief: Self- Care Applications of Horticultural Therapy for Grief Caregivers in Taiwan. Death Studies. Vol. 38, 603-611.

[14] Birren, Faber (1969). Psychological Implications of Color and Illumination. Journal of IES. 397-402. 